\title{
Antituberculosis Drug Resistance in Pulmonary Isolates of Mycobacterium tuberculosis, Cuba 2012-2014
}

\author{
Dihadenys Lemus MS PhD, Miguel Echemendía, Raúl Díaz MS PhD, María Josefa Llanes MD, Lourdes Suárez MD MS, \\ Antonio Marrero MD
}

\begin{abstract}
INTRODUCTION Systematic surveillance of antituberculosis drug resistance allows identification of multidrug-resistant and extensively drug-resistant isolates of Mycobacterium tuberculosis. Surveillance studies of antituberculosis drug resistance systematically conducted in Cuba for over 15 years have revealed low circulation of multidrugresistant tuberculosis, under $1 \%$ in new cases.

OBJECTIVE Characterize antituberculosis drug resistance in isolates of $M$. tuberculosis recovered from patients with pulmonary tuberculosis in Cuba in 2012-2014.

METHODS The nitrate reductase assay was used to test 997 isolates of $M$. tuberculosis for sensitivity to isoniazid and rifampicin. Isolates identified as multidrug resistant were tested for sensitivity to isoniazid, rifampicin, streptomycin, ethambutol, ofloxacin, amikacin, kanamycin and capreomycin by the proportion method, as well as genetic resistance mutations in rpoB, katG, inhA, gyrA, rrs and embB genes, using GenoType MTBDRplus and MTBDRs/ commercial kits.
\end{abstract}

RESULTS Some $95.6 \%$ of isolates from new cases and $89.6 \%$ of isolates from previously treated patients were sensitive to isoniazid and rifampicin. Multidrug resistance was found in $0.8 \%$ of new and $5.2 \%$ of previously treated patients, a statistically significant difference. One extensively drug-resistant isolate was detected among previously treated cases. All isolates examined with the molecular method had mutations in the rpoB gene, which is associated with resistance to rifampicin; only seven showed mutations in the katG gene and one in the inhA gene associated with isoniazid resistance. In one isolate, we found mutations in both gyrA and rrs genes, which are associated with resistance to fluoroquinolones and second-line injectable drugs and therefore, extensive resistance.

CONCLUSIONS Results corroborate the low frequency of multidrugresistant and extensively resistant $M$. tuberculosis strains in Cuba and highlight the need for continuous improvement of surveillance of antituberculosis drug resistance in Cuba.

KEYWORDS Mycobacterium tuberculosis, multidrug resistance, extensively drug-resistant tuberculosis, Cuba

\section{INTRODUCTION}

Tuberculosis (TB), a disease caused by Mycobacterium tuberculosis, is a serious public health problem worldwide, the second leading infectious cause of death after HIV.[1,2] The discovery of antituberculosis drugs in the last century led to a substantial reduction in TB morbidity and mortality, but emergence and spread of strains resistant to first- and second-line antituberculosis drugs are currently important obstacles to TB control worldwide.[1,2]

M. tuberculosis drug resistance happens naturally as a result of spontaneous genetic mutations occurring in the bacterial chromosome. Resistant mutations are rare in wild $M$. tuberculosis populations, but inadequate use of drugs for treatment has led to an increase in resistant strains.[3]

Current knowledge of $M$. tuberculosis drug resistance is the result of implementation of the Global Project on Anti-Tuberculosis Drug Resistance Surveillance, launched in 1994 to collect and assess data on antituberculosis drug resistance systematically and continuously worldwide. Surveillance can be conducted by systematically applying sensitivity tests to all patients diagnosed with TB or by carrying out periodic surveys using randomly selected samples of diagnosed patients.[4]

According to the WHO 2015 Global Tuberculosis Report, there were an estimated 9.6 million new TB cases worldwide in 2014 , $12 \%$ of which were HIV-positive.[2] Resistance surveillance data indicate that multidrug-resistant (MDR, resistant to at least isoniazid and rifampicin) TB occurred in $3.3 \%$ of new cases and in $20 \%$ of patients with a history of antituberculosis drug treatment. As in previous years, the highest numbers of MDR-TB were recorded in Eastern Europe and Central Asia. At the global level, $12 \%$ of

2.7 million bacteriologically-confirmed new cases and $58 \%$ of 0.7 million previously treated cases identified in 2014 underwent sensitivity tests, an increase over 2013 , when $8.9 \%$ of new and $17 \%$ of previously treated cases had sensitivity tests.[1,2] Extensive drug resistance (XDR) was identified in $9.7 \%$ of MDR cases, with resistance also to a fluoroquinolone (FQ) and one of the secondline injectable drugs. By 2014, at least one case of XDR-TB had been reported in 105 countries.[2]

Detection and treatment of MDR-TB remains top priority for TB control in the Americas. In 2011, 29 of the Region's 35 countries reported data on performance of sensitivity assays. Coverage was poor, with assays done in only $11 \%$ of new and $19 \%$ of previously treated cases.[5] In 2012, there were approximately 7000 cases of MDR-TB in the Americas Region, representing approximately $2 \%$ of new pulmonary cases and $14 \%$ of previously treated pulmonary cases. Peru and Brazil reported half of all estimated MDR-TB cases.[6] Drug resistance surveillance should be strengthened in the Americas Region by performing resistance surveys in countries that lack reliable data, and through continuous resistance surveillance whenever possible.

In Cuba, as part of WHO's post-2015 strategy, progress is being made towards TB elimination and continuous TB-resistance surveillance has been implemented. This activity, a vital element of the National TB Control Program (PNC), has revealed low MDR-TB prevalence. A study carried out in 2000-2009 showed $0.4 \%$ MDR-TB in new cases and $8.8 \%$ in previously treated cases,[7] while for these same categories, a 2010-2011 study revealed $1 \%$ and $10.4 \%$, respectively, and found two XDR isolates (the first XDR detected in Cuba).[8] Although MDR-TB numbers detected in Cuba have been low, systematic and timely 
sensitivity testing of $M$. tuberculosis isolates-from both new and previously treated cases-constitutes a priority for PNC and the National Tuberculosis, Leprosy and Mycobacteria Reference and Research Laboratory (LNRITLM) of the Pedro Kourí Tropical Medicine Institute (IPK).[9]

At present a wide variety of methods, both phenotypic and genotypic, are used to test for antituberculosis drug sensitivity. Among these are methods based on solid medium (proportion method, or PM, in Löwenstein-Jensen or agar medium; resistance ratio method; and absolute concentration method) and in liquid culture medium. These methods are easily reproducible and their in vitro results correlate well with clinical course. The limitation of methods using solid medium is that they require several weeks of incubation due to $M$. tuberculosis's slow growth, while the newer methods in liquid medium (BACTEC MGIT 960, Becton-Dickinson Diagnostics, USA and VersaTREK, Thermo Scientific, USA) provide results more quickly (8-12 days),[10] but are very expensive because they are based on automated systems, limiting their adoption in many countries. $[11,12]$

Understanding the molecular mechanisms of M. tuberculosis resistance has led to development of molecular tools, ranging from commercial systems (INNO-LiPA Rif.TB, INNO Genetics, Belgium, Genotype MTBDRplus and Genotype MTBDRsl, Hain Lifescience $\mathrm{GmbH}$, Germany) to nucleic acid sequencing methods. Such methods are faster (not requiring bacterial culture, they can be done in a matter of hours) and highly sensitive, but their introduction in many countries is limited, since they require specific laboratory infrastructure and sophisticated equipment unavailable in countries with limited resources.[11,12]

Recently, WHO approved a group of alternative methods to investigate sensitivity to isoniazid and rifampicin; among these are the nitrate reductase assay (NRA), colorimetric assays using redox indicators, and the microscopic-observation drug-susceptibility assay.[13]

For many years surveillance of antituberculosis drug resistance in Cuba was carried out using PM in Löwenstein-Jensen medium. WHO approval in 2011 of several alternative methods for detection of isoniazid and rifampicin resistance permitted incorporation of new tools for Cuba's resistance surveillance, which LRITLM now conducts using NRA and the molecular assay Genotype MTBDRplus to rapidly ( $\leq 5$ hours) identify cases with resistance to isoniazid and rifampicin, while PM is reserved for sensitivity testing of second-line drugs and ethambutol.[9,13]

This study aimed to characterize antituberculosis drug resistance in isolates of $M$. tuberculosis from patients with bacteriologically confirmed pulmonary TB in Cuba in 2012 - 2014.

\section{METHODS}

We conducted an observational, cross-sectional study of 1472 isolates of $M$. tuberculosis from new cases and previously treated cases (relapses, therapeutic failures and losses to followup) of bacteriologically confirmed pulmonary TB, received at LNRITLM between January 1, 2012 and December 31, 2014. Isolates were received from Cuba's 15 Provincial Hygiene, Epidemiology and Microbiology Centers, the Isle of Youth Municipal Center, the National Pulmonology Hospital and the Diagnostic Unit of the IPK
LNRITLM. One isolate per patient was selected from among those received. Contaminated isolates and those containing fewer than 10 colonies were discarded. The final study sample consisted of 1068 isolates.

Each isolate was accompanied by a form completed by officials of PNC and the provincial laboratories, per PNC norms. For new and relapsed cases, isolates were obtained from cultured samples before starting treatment. For patients classified as treatment failures or lost to followup, isolates obtained from a sample taken prior to start of next treatment or within the first two weeks after its onset were analyzed.[9]

All isolates were studied for isoniazid and rifampicin sensitivity by NRA in Löwenstein-Jensen medium, using critical concentrations of $0.2 \mu \mathrm{g} / \mathrm{mL}$ and $40 \mu \mathrm{g} / \mathrm{mL}$, respectively.[14] MDR isolates were studied by PM in Löwenstein-Jensen medium[15] for sensitivity to the following (critical concentrations for each in parentheses): streptomycin $(4 \mu \mathrm{g} / \mathrm{mL})$, ethambutol $(2 \mu \mathrm{g} / \mathrm{mL})$, ofloxacin $(2 \mu \mathrm{g} /$ $\mathrm{mL})$, kanamycin $(30 \mu \mathrm{g} / \mathrm{mL})$, amikacin $(30 \mu \mathrm{g} / \mathrm{mL})$ and capreomycin $(40 \mu \mathrm{g} / \mathrm{mL})$, as well as to confirm sensitivity to isoniazid $(0.2$ $\mu \mathrm{g} / \mathrm{mL})$, and rifampicin $(40 \mu \mathrm{g} / \mathrm{mL})$.[16] All drugs were supplied by Sigma-Aldrich, Germany. Isolates monoresistant by NRA were analyzed for sensitivity to isoniazid and rifampicin using PM to confirm results.

The quality of each batch of culture medium used was verified for both NRA and PM, using M. tuberculosis strains of known sensitivity. For first-line drugs, M. tuberculosis strains ATCC 35822, ATCC 35820 , ATCC 35837 and ATCC 35838, carriers of monoresistance to isoniazid, streptomycin, ethambutol and rifampicin, respectively, were used. For second-line drugs, strains with known resistance to ofloxacin, amikacin, kanamycin and capreomycin from Argentina's Supranational Reference Laboratory were used, provided in 2009-2010 for external quality control of sensitivity tests. This quality control is carried out annually as part of the Global Project. M. tuberculosis strain H37Rv (ATCC 27294) sensitive to first- and second-line antituberculosis drugs was also used.[4]

Isolates identified as MDR by NRA were examined for mutations in the rpoB, katG, inhA, gyrA, rrs and embB genes using the commercial kits Genotype MTBDRplus and MTBDRsl, according to manufacturer's instructions.[17,18] The Genotype MTBDRplus assay was used as an initial technique to test for resistance to izoniazid and rifampicin in isolates highly suspicious for MDR-TB.

Ethics This study was in PNC's work plan and part of a project in the Ministry of Public Health's program Advanced Techniques Applied to Diagnosis and Laboratory Investigation of $M$. tuberculosis and Other Mycobacteria (code: 131091). It was approved by IPK's Research Ethics Committee (IEC-IPK-35-12). Handling of biological material was carried out by qualified personnel knowledgeable about biosafety standards for working with pathogenic microorganisms. All isolate manipulation was carried out in class II safety cabinets, which prevented external release of pathogenic microorganisms. Patient names and results were kept strictly confidential. Medical personnel responsible for patient care were informed of study results in a timely manner.

Analysis All information was processed in a Microsoft Excel database for Windows, and analysis was performed using EPIDAT 
version 3.1 for epidemiological analysis of tabular data. Results were expressed in absolute numbers and percentages. The Fisher exact test was used to compare proportions of resistance in new and previously treated cases, with a significance threshold of 0.05 .

\section{RESULTS}

Of the 1068 M. tuberculosis isolates studied, 71 were nonviable, and in 7 cases it was impossible to determine whether or not there was prior history of antituberculosis drug treatment. Sensitivity analysis was thus restricted to 990 isolates, of which 836 were from new and 154 from previously treated patients (Table $1)$. Among the latter, there were 111 relapses, 11 treatment failures and 32 followup losses. Of the cases reported in 2012, 2013 and $2014,58.8 \%, 74.5 \%$ and $64.5 \%$ of new cases and $78.3 \%, 87.7 \%$ and $92.6 \%$ of previously treated cases, respectively, were studied.
Table 3 describes mutations found and resistance patterns identified using the Genotype MTBDRplus assay. Deviation from the wild-type rpoB gene was documented in all 14 isolates examined, corroborating phenotypic resistance to rifampicin found by NRA and PM. In 10 isolates, resistance was caused by the MUT3 (S531L) mutation. This mutation was found in six of the seven new case isolates. For the seven isolates from previously treated patients, rifampicin resistance was due to the MUT2B (H526D) mutation in two cases, and MUT3 (S531L) in four cases. Absence of hybridization with the WT2 probe, as well as the absence of the WT2 and WT3 bands, characterized rifampicin resistance of two isolates, one belonging to a previously treated case and the other to a new case. In neither of these cases was a mutation band present.

With respect to isoniazid, we observed deviation from the wild pattern of the katG gene in 10 isolates, but only 7 displayed the MUT1 (S315T1) mutation band (Table $3)$. With respect to the inhA gene, the

Table 1: Isoniazid and/or rifampicin sensitivity of $M$. tuberculosis isolates, Cuba, 2012-2014

\begin{tabular}{|c|c|c|c|c|c|c|c|c|c|c|}
\hline \multirow{2}{*}{ Year } & \multicolumn{5}{|c|}{ New cases } & \multicolumn{5}{|c|}{ Previously treated cases } \\
\hline & $\mathbf{n}$ & $\begin{array}{c}\text { Sensitive } \\
\text { n (\%) }\end{array}$ & $\begin{array}{l}\text { INH-R } \\
\text { n (\%) }\end{array}$ & $\begin{array}{l}\text { RMP-R } \\
\text { n (\%) }\end{array}$ & $\begin{array}{l}\text { MDR } \\
\text { n (\%) }\end{array}$ & n & $\begin{array}{c}\text { Sensitive } \\
\text { n (\%) }\end{array}$ & $\begin{array}{l}\text { INH-R } \\
\text { n (\%) }\end{array}$ & $\begin{array}{c}\text { RMP-R } \\
\text { n (\%) }\end{array}$ & $\begin{array}{l}\text { MDR } \\
\text { n (\%) }\end{array}$ \\
\hline $\begin{array}{l}2012 \\
(n=308)\end{array}$ & 261 & $\begin{array}{r}252 \\
(96.6)\end{array}$ & $\begin{array}{r}4 \\
(1.5)\end{array}$ & $\begin{array}{r}5 \\
(1.9)\end{array}$ & $\begin{array}{r}2 \\
(0.9)\end{array}$ & 47 & $\begin{array}{r}41 \\
(87.2)\end{array}$ & $\begin{array}{r}2 \\
(4.3)\end{array}$ & $\begin{array}{r}4 \\
(8.5)\end{array}$ & $\begin{array}{r}4 \\
(8.5)\end{array}$ \\
\hline $\begin{array}{l}2013 \\
(n=331)\end{array}$ & 274 & $\begin{array}{r}260 \\
(94.9)\end{array}$ & $\begin{array}{r}10 \\
(3.7)\end{array}$ & $\begin{array}{r}4 \\
(1.5)\end{array}$ & $\begin{array}{r}2 \\
(0.7)\end{array}$ & 57 & $\begin{array}{r}49 \\
(86.0)\end{array}$ & $\begin{array}{r}5 \\
(8.8)\end{array}$ & $\begin{array}{r}3 \\
(5.3)\end{array}$ & $\begin{array}{r}2 \\
(3.5)\end{array}$ \\
\hline $\begin{array}{l}2014 \\
(n=351)\end{array}$ & 301 & $\begin{array}{r}287 \\
(95.4)\end{array}$ & $\begin{array}{r}9 \\
(3.0)\end{array}$ & $\begin{array}{r}5 \\
(1.7)\end{array}$ & $\begin{array}{r}3 \\
(1.0)\end{array}$ & 50 & $\begin{array}{r}48 \\
(96.0)\end{array}$ & 0 & $\begin{array}{r}2 \\
(4.0)\end{array}$ & $\begin{array}{r}2 \\
(4.0)\end{array}$ \\
\hline $\begin{array}{l}\text { Total } \\
(\mathrm{n}=990)\end{array}$ & 836 & $\begin{array}{r}799 \\
(95.6)\end{array}$ & $\begin{array}{r}23 \\
(2.8)\end{array}$ & $\begin{array}{r}14 \\
(1.7)\end{array}$ & $\begin{array}{r}7 \\
(0.8)\end{array}$ & 154 & $\begin{array}{r}138 \\
(89.6)\end{array}$ & $\begin{array}{r}7 \\
(4.6)\end{array}$ & $\begin{array}{r}9 \\
(5.8)\end{array}$ & $\begin{array}{r}8 \\
(5.2)\end{array}$ \\
\hline
\end{tabular}

MUT1 (C15T) band was present in a single isolate from a new case (Table 3). Use of the Genotype MTBDRplus assay allowed identification of MDR in 11 isolates $(78.6 \%)$ (Table 3$)$.

Finally, the use of the Genotype MTBDRs/ assay revealed deviation from the wild pattern of the gyrA gene in two phenotypically ofloxacin resistant isolates. The WT3 band was not present in any of them. This finding was accompanied by the MUT3B band in one of the isolates. Concerning the rrs gene, the WT1 band was not present in either of the two isolates with phenotypic INH-R: isoniazid resistant (includes MDR)
MDR: multidrug resistant

RMP-R: rifampicin resistant (includes MDR)

Among new TB case isolates, 95.6\% (799/836) were sensitive to isoniazid and rifampicin, and $0.8 \%$ (7/836) were identified as MDR. Among isolates from previously treated patients, $89.6 \%$ $(138 / 154)$ were sensitive to isoniazid and rifampicin and $5.2 \%$ $(8 / 154)$ were confirmed as MDR (Table 1$)$, all relapses. Resistance to isoniazid was found in two patients whose treatment histories were not available (not included in Table 1).

The difference between the percentages of resistance in new $(4.4 \%)$ and previously treated $(10.4 \%)$ cases was statistically significant $(p=0.0043)$.

PM confirmed resistance in all isolates for which resistance to isoniazid and rifampicin was detected by NRA. Of 15 isolates identified as MDR, one became nonviable and thus could not be studied by other methods used in this study. Table 2 shows sensitivity patterns to other antituberculosis drugs in 14 viable isolates identified as MDR. Among the seven new cases, we identified one isolate sensitive to all drugs, two streptomycin-monoresistant isolates, three isolates resistant to streptomycin and ethambutol, and one resistant to all drugs except ofloxacin. Among the seven isolates of previously treated cases, two were monoresistant to streptomycin, and resistance to ofloxacin was found in another two, one of which was also resistant to capreomycin, kanamycin and ethambutol, showing XDR characteristics. The remaining three isolates were sensitive to all antibiotics. Amikacin resistance could not be assessed in 6 of the 14 cases. resistance to amikacin, kanamycin and capreomycin, and the A1401G (MUT1) mutation was present in both isolates. In three

Table 2: Sensitivity to antituberculosis drugs detected by proportions method, in MDR isolates of M. tuberculosis, Cuba, 2012-2014

\begin{tabular}{|c|c|c|c|c|c|c|c|}
\hline \multirow{2}{*}{$\begin{array}{l}\text { Treatment } \\
\text { history }\end{array}$} & \multirow{2}{*}{$\begin{array}{c}\text { Isolates } \\
n\end{array}$} & \multicolumn{6}{|c|}{ Antituberculosis drugs } \\
\hline & & STR & EMB & OFL & CAP & KAN & AMK \\
\hline \multirow{6}{*}{ New case } & 1 & $\mathrm{~S}$ & S & $\mathrm{S}$ & S & $\mathrm{S}$ & S \\
\hline & 1 & $\mathrm{R}$ & S & S & S & S & S \\
\hline & 1 & $\mathrm{R}$ & S & S & $\mathrm{S}$ & S & ND \\
\hline & 1 & $\mathrm{R}$ & $\mathrm{R}$ & $\mathrm{S}$ & $\mathrm{S}$ & S & ND \\
\hline & 2 & $\mathrm{R}$ & $\mathrm{R}$ & $\mathrm{S}$ & S & $\mathrm{S}$ & $\mathrm{S}$ \\
\hline & 1 & $\mathrm{R}$ & $\mathrm{R}$ & S & $\mathrm{R}$ & $\mathrm{R}$ & $\mathrm{R}$ \\
\hline \multirow{6}{*}{$\begin{array}{l}\text { Previously } \\
\text { treated }\end{array}$} & 2 & S & S & $\mathrm{S}$ & $\mathrm{S}$ & S & ND \\
\hline & 1 & $S$ & S & $\mathrm{S}$ & $\mathrm{S}$ & $S$ & $\mathrm{~S}$ \\
\hline & 1 & $\mathrm{R}$ & $S$ & $S$ & $S$ & $\mathrm{~S}$ & ND \\
\hline & 1 & $\mathrm{R}$ & S & $\mathrm{S}$ & $S$ & $S$ & $\mathrm{~S}$ \\
\hline & 1 & $\mathrm{R}$ & $S$ & $\mathrm{R}$ & $S$ & $S$ & $S$ \\
\hline & $1^{*}$ & S & $\mathrm{R}$ & $\mathrm{R}$ & $\mathrm{R}$ & $\mathrm{R}$ & ND \\
\hline $\begin{array}{l}{ }^{*} \text { Extensively d } \\
\text { AMK: amikacin } \\
\text { ND: not done } \\
\text { STR: streptom }\end{array}$ & \multicolumn{2}{|c|}{$\begin{array}{l}\text { CAP: capreomycin } \\
\text { OFL: ofloxacin }\end{array}$} & \multicolumn{2}{|c|}{$\begin{array}{l}\text { EMB: ethambutol } \\
\text { R: resistant }\end{array}$} & \multicolumn{3}{|c|}{$\begin{array}{l}\text { KAN: kanamycin } \\
\text { S: sensitive }\end{array}$} \\
\hline
\end{tabular}




\section{Original Research}

Table 3: Mutations in rpoB, katG and inhA genes and sensitivity to rifampicin and isoniazid in MDR M. tuberculosis isolates, Cuba, 2012-20104

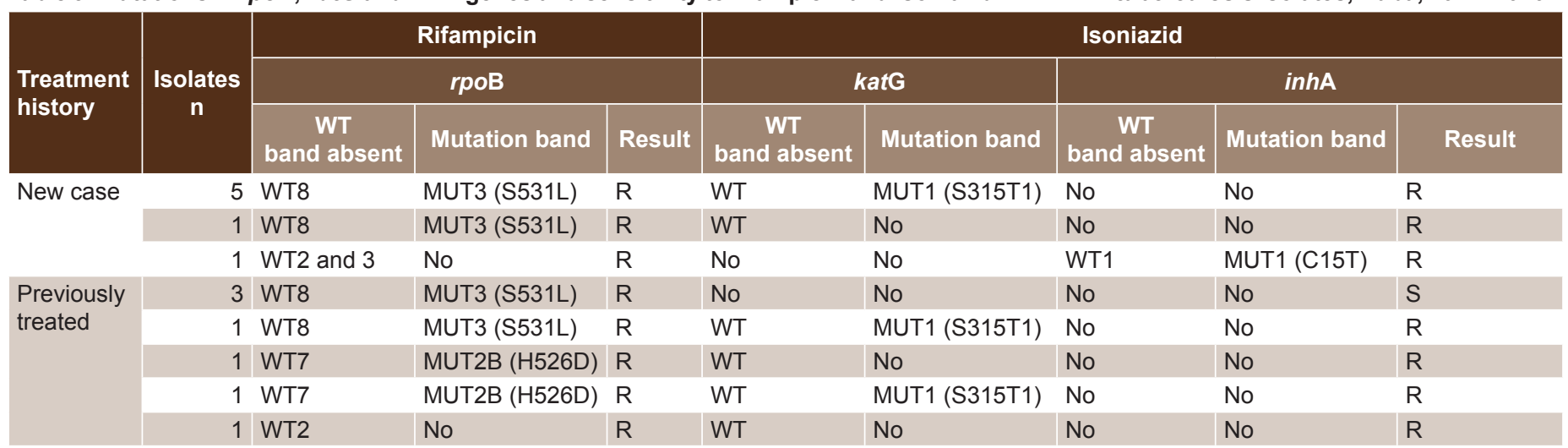

MDR: multidrug resistant MUT: mutation R: resistant S: sensitive WT: wild type

of the five isolates phenotypically resistant to ethambutol, mutations were found in the embB gene with the MUT1B (M306V) mutation.

\section{DISCUSSION}

It is not surprising that PM confirmed isoniazid and rifampicin resistance in all isolates identified as resistant by NRA. Use of NRA at LNRITLM for several consecutive years showed excellent results for timely detection of resistance, not only to isoniazid and rifampicin, but also to streptomycin, ethambutol and second-line antituberculosis drugs.[8,19,20] Likewise, González (Colombia) recognizes the usefulness of NRA and reports a sensitivity of $91 \%$ and $92 \%$ for detection of resistance to isoniazid and rifampicin, respectively, as well as specificity of $100 \%$ for both drugs, compared to PM.[21]

MDR-TB rates detected in this study, both in new $(0.8 \%)$ and previously treated cases $(5.2 \%)$, are consistent with earlier LNRITLM reports of low circulating levels of MDR $M$. tuberculosis strains in Cuba.[7,8] The finding of new cases with rifampicin and isoniazid resistance constitutes a warning and points out the importance of searching for possible infection sources in such cases.

In the Americas, between $0 \%$ and $6.6 \%$ of new TB cases were MDR in 2012, the highest proportions reported in the Dominican Republic (6.6\%), Ecuador (4.9\%) and Peru (3.9\%).[6] In countries lacking reliable data, surveillance of drug resistance should be carried out through surveys and, if possible, through continuous surveillance. The proportion of MDR-TB in previously treated cases was between $0 \%$ and $35 \%$, with the highest percentages reported by Peru (35\%) and Puerto Rico (33\%).[6]

Global coverage for sensitivity testing of $F Q$ and second-line injectable drugs is low. Only 23 of the 36 countries with high MDR-TB burden have reported data on resistance to second-line antituberculosis drugs. In 2012, 98 cases of XDR-TB were diagnosed in the Americas Region, a 26\% increase over 2011; Brazil and Peru reported 16 and 67 cases, respectively.[6] To date, three cases of XDR-TB have been identified in Cuba, all in previously treated patients. One case was identified during this study, the two in 2011.[8] By 2014, at least one case of XDR-TB had been reported in 105 countries, with a relative frequency of $9.7 \%$ of MDR-TB cases.[2]
Among MDR-TB cases detected between 2010 and 2014 (including in our study), resistance to ofloxacin was found in four isolates of $M$. tuberculosis (two in this study) and in three of them, it was associated with resistance to second-line injectable drugs.[8]

The global panorama of $M$. tuberculosis resistance confirms the importance of systematically monitoring resistance to first- and second-line antituberculosis drugs. Ideally, sensitivity testing would be carried out before starting antituberculosis treatment, but in most countries, it is impossible to get phenotypic sensitivity study results in a timely manner, so patients receive empirical treatment. Molecular techniques can play an important role by rapidly assessing sensitivity and enabling early administration of optimal treatment regimens, consistent with resistance patterns of each strain.[22,23]

The findings of other authors, also using molecular procedures, coincide with ours in terms of mutations identified and their frequencies. Asencios (Peru) found high sensitivity and specificity of the Genotype MTBDRplus assay when compared to PM in agar. As in our study, S531L and S315T1 mutations were predominantly responsible for resistance to rifampicin and isoniazid, respectively. [24] Feliciano (Brazil) also found predominance of the S531L mutation among rifampicin-resistant isolates, while resistance to isoniazid was due to the S315T1 mutation in $50 \%$ of cases. In the remaining $50 \%$, low resistance was found due to mutations in the inhA gene.[25]

Izoniazid resistance of the MTBDRplus genotype in 11 of the 14 isolates examined suggests the presence of infrequent mutations in the katG and inhA genes, or other molecular resistance mechanisms. Although the role of mutations in the kasA genes and the oxyR-ahpC and furA-katG intergene regions has not been fully elucidated so far, other studies have shown them in isoniazid-resistant isolates; regarding rifampicin, $96 \%$ of resistant strains present mutations in the 81 base pairs region of the rpoB gene.[26] However, there are reports of infrequent mutations outside this region that have also been associated with rifampicin resistance.[25] Our results suggest the need for research to elucidate the molecular mechanisms of resistance in Cuban isolates of $M$. tuberculosis.

In our study, the use of the Genotype MTBDRs/ assay version 1.0 revealed an XDR pattern in a strain by finding mutations in the gyrA and $r$ rs genes. This result was corroborated by demonstration of 
phenotypic resistance to ofloxacin, kanamycin and capreomycin using the reference technique.

Although we found no discordance between PM and the molecular method in sensitivity to second-line antituberculosis drugs, Theron's 2014 meta-analysis reported that the Genotype MTBDRs/ assay, version 1.0, failed to detect approximately one in five $F Q$ resistance cases and one in four second-line injectable drug resistance cases. This assay rarely produces false positives for resistance.[27]

The recently released Genotype MTBDRs/ assay, version 2.0, has advantages over version 1.0. In this version, in addition to the gyrA and rrs genes, mutations in the gyrB gene and in the promoter region of the eis gene are analyzed, increasing sensitivity in detecting $F Q$ and second-line injectable drug resistance, particularly to kanamycin. This assay is a valuable tool, especially once WHO approved a shortened regimen for treatment of MDR-TB, since only patients with documented sensitivity to FQ and injectable drugs would be eligible.[23]

\section{CONCLUSIONS}

Our results suggest a low frequency of MDR $M$. tuberculosis in Cuba. Nonetheless, they warn of the need to continue improving surveillance of antituberculosis drug resistance by gradually increasing the number of isolates studied to ensure that all isolates from new and previously treated cases are tested for drug sensitivity. In addition, they demonstrate the importance of exhaustively searching for possible infection sources when resistant strains are encountered in new TB cases. 1 . 1 -

\section{REFERENCES}

1. World Health Organization. Global tuberculosis control: WHO report 2014. Geneva: World Health Organization; 2014. $171 \mathrm{p}$.

2. World Health Organization. Global tuberculosis control: WHO report 2015. Geneva: World Health Organization; 2015. 192 p.

3. Caminero JA, editor. Guidelines for Clinical and Operational Management of Drug-Resistant Tuberculosis. Paris: International Union Against Tuberculosis and Lung Disease; 2013. 240 p.

4. World Health Organization. Directrices para la vigilancia de la farmacorresistencia en la tuberculosis. 5th ed. Geneva: World Health Organization; 2016. 76 p. Spanish.

5. Pan American Health Organization. La tuberculosis en la Región de las Américas. Informe Regional 2011. Epidemiología, control y financiamiento. Washington, D.C.: Pan American Health Organization; 2011.53 p. Spanish.

6. Pan American Health Organization. La tuberculosis en la Región de las Américas. Informe regional 2013. Epidemiología, control y financiamiento. Washington, D.C.: Pan American Health Organization; 2014. Spanish.

7. Montoro E, Lemus D, Echemendía M, Díaz R, Mederos L, Martínez MR, et al. Vigilancia de la resistencia a los fármacos antituberculosos en Cuba, 2000-2009. Rev Panam Salud Pública. 2011;30(6):615-8. Spanish.

8. Lemus D, Echemendía M, Díaz R, Llop A, Llanes MJ. Vigilancia de la resistencia a los medicamentos antituberculosos en Cuba, 2010-2011. Biomédica. 2014 Apr;34 Suppl1:108-13. Spanish.

9. Ministry of Public Health (CU). Programa Nacional y Normas de Procedimiento para la Prevención y Control de la Tuberculosis. Havana: Ministry of Public Health (CU); 2013. Spanish.

10. Palomino JC. Challenges associated with diagnostics, drug resistance and pathogenesis of Mycobacterium tuberculosis. In: Singh SK, editor. Human Emerging and Re-emerging Infections: Bacterial and Mycotic Infections. 1st ed. New York: John Wiley \& Sons; 2016. Chapter 45. Vol. 2

11. Alcaide F, Esteban J, González-Martín J, Palacios JJ. Métodos de determinación de sensibilidad a los antimicrobianos en micobacterias. Enferm Infecc Microbiol Clin [Internet]. 2016 May [cited $2016 \mathrm{Jul}$ 24]. Available from: http://dx.doi .org/10.1016/j.emc.2016.04.008. Spanish

12. Gaz MA, Islam MR, Kibria MG, Mahmud Z. General and advanced diagnostic tools to detect Mycobacterium tuberculosis and their drug sus- ceptibility: a review. Eur J Clin Microbiol Infect Dis. 2015 May;34(5):851-61.

13. World Health Organization. Noncommercial culture and drug-susceptibility testing methods for screening patients at risk for multidrug-resistant tuberculosis. Geneva: World Health Organization; 2011. $18 \mathrm{p}$.

14. Angeby KA, Klintz L, Hoffner SE. Rapid and inexpensive drug susceptibility testing of Mycobacterium tuberculosis with a nitrate reductase assay. J Clin Microbiol [Internet]. 2002 Feb [cited 2016 Mar 4];40(2):553-5. Available from: http:// dx.doi:10.1128/JCM.40.2.553-555.2002

15. Canetti G, Fox W, Khomenko A, Mahler HT, Menon NK, Mitchison DA, et al. Advances in techniques of testing mycobacterial drug sensitivity, and the use of sensitivity tests in tuberculosis control programs. Bull World Health Organ. 1969;41(1):21-43.

16. World Health Organization. Policy guidance on drug-susceptibility testing of second-line antituberculosis drugs. Geneva: World Health Organization; 2008. 20 p.

17. Hain Lifescience [Internet]. Nehren (DE): Hain Lifescience $\mathrm{GmbH}$; c2016. Products. Genotype ${ }^{\circledR}$ MTBDRplus product insert, VER 2.0 - Your test system for a fast and reliable way to detect MDR-TB; [cited 2016 Apr 24]; [about 1 screen]. Available from: http://www.hain-lifescience.de/ en/products/microbiology/mycobacteria/tuber culosis/genotype-mtbdrplus.html

18. Hain Lifescience [Internet]. Nehren (DE): Hain Lifescience $\mathrm{GmbH}$; c2016. Products. Genotype ${ }^{\circledR}$ MTBDRs/ VER 1.0 and VER 2.0 - Your important assistance for detection of XDR-TB; [cited 2016 Apr 24]; [about 1 screen]. Available from: http:// www.hain-lifescience.de/en/products/microbio logy/mycobacteria/tuberculosis/genotype-mtb drsl.html

19. Lemus D, Montoro E, Echemendía M, Martin A, Portaels F, Palomino JC. Nitrate reductase assay for detection of drug resistance in Mycobacterium tuberculosis: simple and inexpensive method for low resources laboratories. J Med Microbiol. 2006 Jul;55(Pt 7):861-3.

20. Lemus Molina D, Álvarez Echaide Y, Echemendía Font M, Vander Stuyf P, Palomino JC, Martin A. Utilidad del método de la nitrato reductasa para la detección de resistencia a drogas antituberculosas de segunda línea. Rev Cub Med Trop. 2015;67(1). Spanish.

21. González L, Sánchez R, Murcia MI. Utilidad de la prueba de la nitrato reductasa para la detección rá- pida de resistencia en Mycobacterium tuberculosis. Biomédica 2014;34(Suppl 1):232-8. Spanish.

22. Domínguez J, Boettger EC, Cirillo D, Cobelens F, Eisenach KD, Gagneux S, et al. Clinical implications of molecular drug resistance testing for Mycobacterium tuberculosis: a TBNET/RESISTTB consensus statement. Int J Tuberc Lung Dis. 2016 Jan;20(1):24-42.

23. World Health Organization. The use of molecular line probe assays for the detection of resistance to second-line anti-tuberculosis drugs. Policy guidance. WHO/HTM/TB/2016.07. Geneva: World Health Organization; 2016.

24. Asencios L, Galarza M, Quispe N, Vásquez L, Leo E, Valencia E, et al. Prueba molecular Genotype ${ }^{\circledR}$ MTBDRplus, una alternativa para la detección rápida de tuberculosis multidrogorresistente. Rev Peru Med Exp Salud Publica. 2012 Jan-Mar;29(1):92-8. Spanish.

25. Feliciano CS, Nascimento MM, Anselmo LM, Pocente RH, Bellissimo-Rodrigues F, Bollela VR. Role of a GenoType MTBDRplus line probe assay in early detection of multidrug-resistant tuberculosis at a Brazilian reference center. Braz J Med Biol Res. 2015 Aug;48(8):759-64.

26. Palomino JC, Martin A. Drug resistance mechanisms in Mycobacterium tuberculosis. Antibiotics (Basel). 2014 Jul 2;3(3):317-40.

27. Theron G, Peter J, Richardson M, Warren R Dheda K, Steingart KR. GenoType ${ }^{\circledR}$ Mtbdrsl assay for resistance to second-line anti-tuberculosis drugs. Cochrane Database of Syst Rev. 2016 Sep 8;9:CD010705. DOI:10.1002/14651858. CD010705.pub3

\section{THE AUTHORS}

Dihadenys Lemus Molina (Corresponding author: dlemus@ipk.sld.cu, dihadenys@infomed. sld.cu), microbiologist with a master's degree in bacteriology and mycology and doctorate in health sciences. Assistant professor and senior researcher, Department of Bacteriology and Mycology; National Tuberculosis, Leprosy and Mycobacteria Reference and Research Laboratory (LNRITLM); Pedro Kourí Tropical Medicine Institute (IPK); Havana, Cuba.

Miguel Echemendía Font, Research technician. Associate technical instructor, Department of Bacteriology and Mycology, LNRITLM, IPK, Havana, Cuba. 
Raúl Díaz Rodríguez, biochemist with a master's degree in bacteriology and mycology and doctorate in health sciences. Full professor and senior researcher, LNRITLM, IPK, Havana, Cuba.

María Josefa Llanes Cordero, physician specializing in epidemiology. National Epidemiology Division; Hygiene, Epidemiology and Microbiology Branch; Ministry of Public Health (MINSAP); Havana, Cuba.
Lourdes Suárez Álvarez, family physician with a master's degree in epidemiology. National Epidemiology Division; Hygiene, Epidemiology and Microbiology Branch; MINSAP; Havana, Cuba.

Antonio Marrero Figueroa, physician specializing in epidemiology. National Epidemiology Division; Hygiene, Epidemiology and Microbiology Branch; MINSAP; Havana, Cuba.
Submitted: June 28, 2016

Approved for publication: December 14, 2016

Disclosures: None

\section{Scientific Publishing in the Informatics Age 11th Meeting of Editors of Scientific Journals and Magazines}

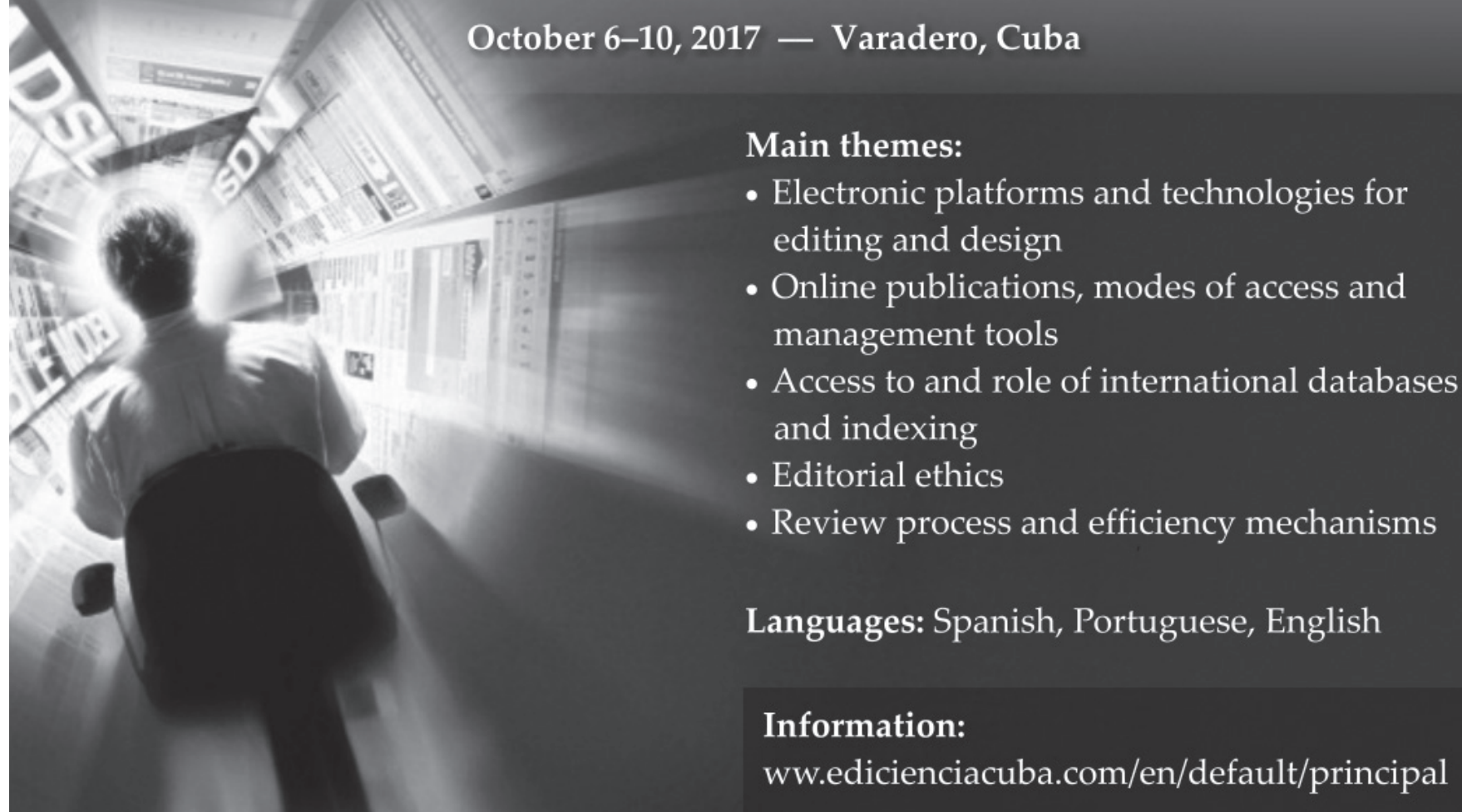

